\section{Views sought on periodontal furcation}

$B D J$ readers are invited to participate in a research project about dentists' attitudes towards periodontal furcation involvement. The survey takes no longer than ten minutes and consists of simple questions about your attitude towards furcation involvement. In taking part, you will be contributing to periodontal research taking place at King's College London and collaborating centres. Your help is much appreciated.

Click on the following link to participate in the survey: https://kcldental.qualtrics. com/jfe/form/SV_bI4SzWoHP2Kto6F.

\section{BADT and BSDHT contact GDC Council members}

\author{
The British Association of Dental \\ Therapists (BADT) and the British \\ Society of Dental Hygiene and Therapy \\ (BSDHT) have taken the unusual step \\ of directly contacting each appointed \\ Council member of the General \\ Dental Council (GDC) regarding \\ overseas dentists registering as dental \\ therapists and dental hygienists without \\ any practical assessment of clinical \\ skills. Both BADT and BSDHT feel \\ that continuing interactions with the \\ executive function of the GDC regarding \\ this matter have failed to produce any \\ positive movement towards change in \\ a situation that both organisations feel \\ compromises patient safety. By directly \\ raising awareness to the appointed \\ Council members, BADT and BSDHT \\ hope to move the discussion into the \\ public forum to ensure change, in order \\ to 'protect patient safety and maintain \\ public confidence in dental services'.
}

\title{
BAOMS supports DCTs to enter maxillofacial surgery
}

Consultant OMFS Muzzammil Nusrath has kicked off his campaign to encourage dental students to aim for a career in OMFS by highlighting the support available.

Dr Nusrath, Training Programme Director (TPD) for Dental Core Training (DCT) in oral and maxillofacial surgery (OMFS) and Regional Advisor for the Royal College of Physicians \& Surgeons of Glasgow, said: 'Oral and maxillofacial surgery is the exciting surgical interface between medicine and dentistry. Degrees in both disciplines are required to enter OMFS training. Many students are put off doing this because of the time taken to qualify and the expense of self-financing their second degree, but there is a lot of help available from the British Association of Oral and Maxillofacial Surgery (BAOMS), including bursaries from BAOMS and the NHS to support students to take their second degree.

'Further financial support is available through regular and locum work in OMFS units that is prioritised specifically for trainees pursuing second degrees. And, don't forget, UK OMFS training is recognised globally as one of the best'.

Anne Begley, BAOMS Council Member whose portfolio is focused on supporting DCTs, is the driving force behind building a web-based resource for those involved in the clinical and/or educational supervision of DCTs' training: 'I want to help improve the experience of DCTs who work in OMFS units. I need contributions and help from all levels and grades of members of BAOMS - our DCTs are the consultant colleagues of the future.

'Our new Foundation Training in Oral and Maxillofacial Surgery (FTOMS) programme gives a checklist of OMFS experience and training that anyone can follow, particularly DCTs. Trainees can register their interest in OMFS, which is free of charge, and this allows trainees to build up their portfolio whatever their career plans. They get a certificate for participating or completing it.'

Degrees in both medicine and dentistry are required to enter specialty training in oral and maxillofacial surgery. Most students work either as a qualified dentist or doctor during their second degree years. Shorter second degrees are available that last between three and four years.

Dr Nusrath's advice to DCTs is: 'Get yourself an elective/DCT post in an OMFS department in a university that links to a medical school. Once you decide that OMFS is the career for you, plan early for the second degree in medicine. The remit of the specialty is vast and ranges from craniomaxillofacial trauma, facial deformity, cleft lip and palate, dentoalveolar surgery, craniofacial implants, salivary gland disease, head and neck cancer with reconstruction, facial aesthetics and craniomaxillofacial surgery. The trainees can then choose the right subspecialty of OMFS that they would like to pursue.

'Dedication and the right attitude are required to pursue the subspecialty of head and neck cancer surgery. But oral and maxillofacial surgery is a highly rewarding specialty where trainees learn an incredible amount of skills, and have the satisfaction of treating cancer patients - this cannot be replaced by any amount of money'.

The leaflet Have you considered a career in maxillofacial surgery? is available at: https:// bit.ly/2PU7J3d.

BAOMS offers student bursaries for second degree students, who are student members of BAOMS. The main bursary amount is up to $£ 2,000$. The number of annual awards made varies, but is usually between 10 to 15. Bursary projects are uploaded onto the BAOMS website: https://bit.ly/2Cyvo6a.

For further information visit https://bit. ly/3kMzp8f.

\section{UDC experiences required for research study}

A team of researchers from the University of Plymouth are conducting a research study aiming to explore the experiences of dentists and dental nurses in providing care at Urgent Dental Care (UDC) centres during the COVID-19 pandemic. To find out more about the study and/or take part please visit https://www.plymouth.ac.uk/ research/experiences-of-providing-care-at-urgentdental-centres-in-england-during-the-covid-19pandemic or email dental.hubs@plymouth.ac.uk.

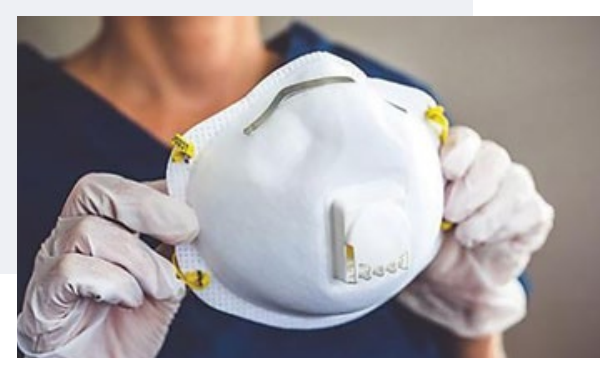

221 